\title{
A Study on Management Model of Human Resources in Multinational Companies Based on Cultural Differences -- Taking Walmart as an Example
}

\author{
Xiaonan Song \\ School of Foreign Languages, Northwest University of Political Science and Law, Shanxi Xi'an \\ 710122, China.
}

767926869@qq.com

Keywords: human resource management, cultural differences, model study.

\begin{abstract}
With the globalization of the economy, enterprises of various countries inevitably move towards the road of globalization and form transnational corporations gradually. In the process of operation, transnational corporations would face the employees who are with different backgrounds. Cultural differences have posed a great challenge to HRM of transnational corporations. Beginning with Walmart's human resource management model, this paper explores the possible human resource management model of multinational companies based on cultural differences.
\end{abstract}

\section{Introduction}

Nowadays, cultural differences have become one of the biggest challenges for multinational companies to invest in different cultural areas. The conflicts between culture of multinational companies and Chinese culture are obvious and extensive. The root cause of the conflicts is that the two organizational cultures are rooted in two different social, economic and political systems respectively, leading to the contradictions between the basic beliefs and norms of behavior. There are many things behind the cultural conflicts, which are not a superficial problem of cultural communication.

\section{Human Resource Management in International Operation}

With the expansion of enterprises' international operations, more and more enterprises have realized that human resource is the most valuable resource in international operation and it also has the decisive role in many other things. At the same time they also recognize that, when business across multiple cultures, the original system of management would encounter cultural differences inevitably. If the processes couldn't be well treated, it will cause fatal damage to business. Especially for the human resources management system, the influence of culture is mainly made by artificial medium, therefore, how to establish a scientific and effective human resources management system based on the cultural differences, then discover and cultivate talents, also put the talents of all trained personnel to rational use has become a problem that each multinational company cannot be ignored when making development strategies.

Human resourcing management has had the change led by international operation, improving urvival and adaptation ability of organizations and employees under the background of different cultures, and enhancing the affinity of organizations around the world and the inner cohesion, also fostering the world of ideal personality type "cultural marginal people" to become the important task of multinational company human resourcing management.

\section{The Influence of Cultural Differences on Transnational Corporations}

The biggest problem that HRM in multinational companies faced is the ubiquitous cultural differences in the daily operations of the companies. To some extent, the human resource 
management of transnational corporations is cross-cultural human resource management. It is embodied four aspects as followed:

\subsection{Problems in the Recruitment Process.}

In the process of recruitment, both the determination of the companies' management level and the employment of ordinary employees would be affected by cultural differences more or less.

First of all, in terms of management, if you think about the overall global strategies of the company, you should select management candidates from a global perspective. For cultural points of view, however, if external managers would be employed, due to differences in the country cultures, it is easy to conflict with other people, which is not conducive to work.

Secondly, it is the reason that if the cultures different, the methods of ordinary employees also differ greatly. Take the situations of our country as an example. At present, the people in China always prefer to have some backstage support when dealing with things. Foreign companies, on the other hand, intend to use evaluation-centric recruitment model based on IQ tests and competency tests. If these factors are not taken into account, it will be a hindrance to the reserve of talents in companies.

\subsection{Personnel Training Issues.}

People from different cultural backgrounds hold different views on employee training and the training contents are also different. Compared with developed countries, developing countries do not pay special attention to staff training, and employees themselves do not pay enough attention to post-service training to a certain extent. Therefore, multinational companies often encounter situations in which employees with certain cultural backgrounds don't have the reasonable attitude towards training, and some of them even have some conflicts. If cultural differences are not taken into account, only simple training would make the cohesion of the companies weaken.

In addition, for the training contents, employees from different cultural backgrounds should receive corresponding training. For example, the contents of some training are taboos for employees with specific cultural backgrounds or insults to their nationalities, religions and beliefs. In the eyes of other employees, these things are irrelevant. If the company cannot determine the training contents for employees from different cultural backgrounds when determining the training contents, it may lead to a decline in internal cohesion of the company.

\subsection{Problems with Performance Appraisal.}

Performance appraisal is an important way to motivate employees and improve production efficiency. However, cultural differences within transnational corporations may cause problems in personnel appraisal and incentive.

Cultural differences create incentives. Due to the diverse beliefs, ideas, views and attitudes of employees in transnational enterprises, it is difficult to form an incentive which is unified for cross-cultural enterprises. The satisfaction degree of employees with different cultural background is very different to varies of incentives, which let multinational companies find it hard to form a certain incentive and promotion mechanism, what is not conducive to the standardization of the enterprise operation and management.

\subsection{Problems with the compensation System.}

The salary system is a key factor that affects the enterprise whether can retain talents or not. The fairness, reasonableness and objectives of salary affects the long-term development of the enterprise. In the salary management of multinational companies, different values wound have an important influence on the formation of the salary system.

First of all, there is a question of the salary system. Companies from different cultural backgrounds have different starting points for establishing salary system. In China, for example, the emphasis on salary directly links to factors such as seniority and education. In the west, it mainly links to the nature of the job and it can only be adjusted when jobs and contents change.

In addition, laws, regulations and currencies also affect the salary. In multinational company for the employees' compensation and benefits for different countries have different rules, such as some of these rules may be in conflict with the compensation system and the companies' internal rules. 


\section{Walmart's Human Resources Strategies}

\subsection{Retaining Talents.}

Walmart is committed to every employee to provide a good and harmonious working environment, and improve the salary, welfare programs, broad career development space, also it has formed a whole set of unique policy and system.

(1) Partnership policy in Walmart's, employees are not called employees, but "partners". The policies embodied in this concept are embodied in three complementary schemes that is the profit-sharing scheme, the employee share purchase scheme and the loss-reward scheme. Walmart has also introduced many bonus schemes, the most successful of which is the loss-reward scheme. At Walmart, managers and employees are also good partners. The buttons of managers inscribed with the words "we care about our employees" to treat employees. Managers must kindly respect and praise them, and care for them, also listen carefully to their opinions, together with helping them grow and develop sincerely. In short, the partnership is reflected everywhere within Walmart, bringing Walmart together as a whole.

(2) The company attaches great importance to the communication of information, and puts forward and carries through the open door policy. As long as there is an idea or an opinion, the staff in Walmart can be oral or in writing to communicate with management and even the president at any time anywhere, and they don't have to worry about reprisals. Any executive who uses the "open door" policy to retaliate would be subject to severe disciplinary action or even dismissal. The implementation of this policy fully ensures employees' right to participate and lays a solid foundation for Walmart's human resource management information communication.

\subsection{Developing Talents.}

Walmart's managers have realized the importance of talents to the success of enterprises through constant exploration. Strengthening education for employees is an important way to improve the quality of the talents. Therefore, Walmart regards it and placement of existing employees as priorities.

(1) Establish a mechanism of lifelong training. Walmart attaches great importance to the training of employees and education, and establishes an effective mechanism of training, also invests a lot of money to guarantee it. The training contains post training, promotion training, transfer training, global best practice exchange and various special training. Walmart trains its managers in leadership and management skills according to the potential of different employees, who would be the backbone of the companies.

(2) Walmart pays attention to the abilities and teamwork spirit in employing employees. Education background and diploma are not very important. At a general retail company, people without more than 10 years of experience would not even be considered for promotion to Walmart manager. And after six months of training, if their performance is good, and they have the ability of staff management, also they are good at sales, the company will give them the opportunity to try, to do as an assistant manager or to assist in opening new stores, and then if they can done well, they will have the opportunity to manage a branch.

(3) Internal promotion system in the past, Walmart promoted the philosophy of "recruitment, retention and development", but now it has changed to the mode of "reservation, development and recruitment". It is not only a change in semantics, it also shows that the emphasis on retaining and developing the talents who have already possessed by the company is no longer a feature of continuous recruitment in the past. The company expects to maximize the potential of its employees and create opportunities to enrich and expand its work, and to encourage and practice the promotion of managers from within. For the performance of each employee, the HR department will conduct regular evaluation, interview with the employee, and store in personal files.

\subsection{Attracting Talents.}

In addition to selecting existing talents from within the company, Walmart began to introduce senior talents from outside in a timely manner to replenish the company's human resources. Walmart provides equal employment opportunities for every applicant, regardless of race, age, gender, region, 
religion, etc. Since 1998, Walmart began to implement the trainee management program, which is to hold career development lectures in colleges and universities, attracting a large number of outstanding graduates. After a long period of training and then to fill various positions, this greatly alleviates the rapid expansion of the company's business to the needs of talents. With such a brilliant development history and prospect, Walmart's employment methods are worthy of our consideration and reference in China's retail industry. Staff is the main body of the company, we should respect the employees, and establish the benefit sharing partnership with employees, also maximize the mining employees' creative potential to make every employee fully realize personal value and achieve excellence in each work state. In this way can we really make the enterprise stand at a high starting point to achieve large development?

\section{The Strategies That Walmart Can Adopt When Facing Cultural Differences in Human Resource Management}

First of all, we need to notice the gap between traditional personnel management and modern human resource management in China. In the process of joint venture, we should not only introduce capital and technology knowledge, but also introduce effective concepts that were proven by foreigners of human resource management and its tools. On the basis of the concept of "people-oriented", we truly respect employees, and care about them, also provide them with the space for personal development and help them develop in a personalized way.

Secondly, in the introduction of western management ideas, we need to analyze the characteristics of the staff in the enterprise, and attach importance to national culture and even within the same country difference of regional culture, also turn the western human resource management tools to "localization", together with making Chinese employees from emotional ones. Culture and management tools are like the relationship between soil and seeds. If they do not match, seeds will always only be seeds and will not bear fruit.

Thirdly, from the enterprise management of benign and ethnic conflict of national culture, we should establish a results oriented incentive mechanism, and create a good corporate culture to break such as hierarchical, nepotism. We pay attention to performance, such as outdated ideas to improve the efficiency of management.

Finally, in order to realize from affairs workers to strategic partners of the human resources managers, and stand in the level of enterprise strategic thinking, also develop a harmonious and consistent HR strategies and business strategies development, which will guide human resources management in the enterprise systematically so as to avoid the widespread disorder of present enterprise human resources management.

In the modern enterprise, the importance of human resource management has been very prominent, especially in enterprise reform, enterprise culture construction, and improving employee satisfaction. However, there is still a big gap between China and the west in the effectiveness of human resource management. How to improve the quality of management is a long-term problem that we should consider.

\section{References}

[1] Hu Jun. Cross-cultural management [M]. Fuzhou: Jinan University Press, 1996.

[2] [German] Patricia Patel, Scheele. Cross-cultural management [M]. Translated by Yao Yan. Beijing: China Social Science Press, 1998.

[3] Qiu Wen. American and Japanese enterprises -- human resource management model [J] Human Resource Development in China, 2001(10).

[4] [America] John B. Cullen. Multinational management strategies [M]. Beijing: Machinery Industry Press, 2000. 